\title{
GENERATION AND CHARACTERIZATION OF CARBONYL YLIDES FROM PYRAZOLINONE SPIROOXIRANES
}

PESI UMRIGAR and GARY W. GRIFFIN

Department of Chemistry, University of New Orleans, New Orleans, LA 70122 (U.S.A.)

BARBARA A. LINDIG and MARYE ANNE FOX

Department of Chemistry, University of Texas at Austin, Austin, TX 78712 (U.S.A.)

PARITOSH K. DAS, THOMAS M. LESLIE ${ }^{\dagger}$ and ANTHONY M. TROZZOLO

Radiation Laboratory, University of Notre Dame, Notre Dame, IN 46556 (U.S.A.)

SEYHAN N. EḠE and ANTHONY THOMAS

Department of Chemistry, University of Michigan, Ann Arbor, MI 48109 (U.S.A.)

(Received September 13, 1982)

\section{Summary}

Laser flash photolyses of 1-oxa-5,6-diazaspiro[2.4]hept-6-ene-4-ones I ( $\mathrm{Ar} \equiv \mathrm{Ph}, p-\mathrm{NO}_{2} \mathrm{Ph}, p-\mathrm{CH}_{3} \mathrm{OPh} ; \mathbf{R}_{1} \equiv \mathrm{CI}_{3}, \mathrm{Ph} ; \mathbf{R}_{2}, \mathbf{R}_{3} \equiv \mathrm{CII}_{3} ; \mathbf{R}_{2}=\mathrm{Ph}$, $p$ - $\mathrm{NO}_{2} \mathrm{Ph}, p$-ClPh, 2-naphthyl; $\mathrm{R}_{3} \equiv \mathrm{H}$ ) and of the symmetrical oxirane II give rise to transients with absorption spectra in the visible region and lifetimes of the order of $0.3-10 \mu \mathrm{s}$ in benzene at room temperature. Sensitization experiments in some cases indicate that the intermediate may arise from a triplet as well as a singlet excited state. Transients from I are quenched by alcohols and 2,3-dimethyl-2-butene whereas that from II is not. Steady state photolyses of $I$ in methanol give products consistent with the assignment of the structure of the transient as a carbonyl ylide incorporating the pyrazolinone ring.

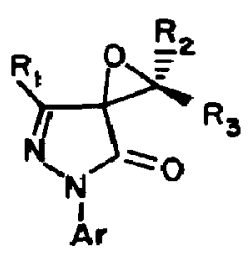

$\mathbf{I}$

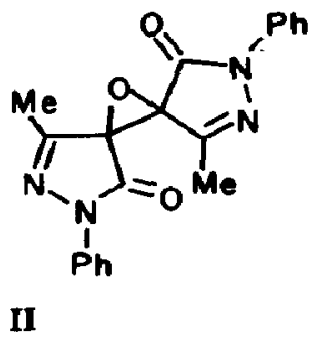

II U.S.A.

†Present address: Bell Laboratories, 600 Mountain Avenue, Murray Hill, NJ 07974, 


\section{Introduction}

The isolation of pyrazolinone spirooxirane 1a as the chief product of the photolysis of 5-methyl-2-phenyl-3-pyrazolidinone in acetone [1] and the failure to obtain an analogous compound bearing an aryl group on the oxirane ring when the irradiation was carried out in the presence of acetophenone encouraged us to investigate the photochemical properties of the heterocyclic spirooxiranes 1 and 2 (Fig. 1). The synthesis of these novel systems and some observations on their ground state chemistry [2], the determination of the stereochemistry of the spirooxiranes [3] and some preliminary results on the photochemistry [4] of these compounds have been reported. Here we examine the physical and chemical properties of the carbonyl ylides 3 (Fig. 2) postulated to arise by fragmentation of the oxirane ring.

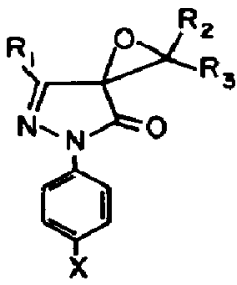

1

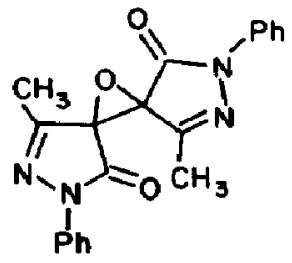

2

Fig. 1. Structure of spirooxiranes 1 and 2: $1 \mathrm{a}, \mathbf{R}_{1}, \mathbf{R}_{2}, \mathbf{R}_{3}=\mathbf{C H}_{3}, \mathrm{X} \equiv \mathbf{H} ; \mathbf{1 b}, \mathbf{R}_{1}, \mathbf{R}_{2}, \mathbf{R}_{3} \equiv$ $\mathrm{CH}_{3}, \mathrm{X} \equiv \mathrm{OCH}_{3} ; \mathbf{1 c}, \mathbf{R}_{1} \equiv \mathbf{P h}, \mathbf{R}_{2}, \mathbf{R}_{3} \equiv \mathbf{C H}_{3}, \mathrm{X} \equiv \mathrm{H} ; \mathbf{1 d}, \mathrm{R}_{1} \equiv \mathbf{C H}_{3}, \mathrm{R}_{2} \equiv \mathbf{P h}, \mathbf{R}_{3} \equiv \mathrm{H}$, $\mathrm{X} \equiv \mathrm{H} ; \mathbf{1 e}, \mathbf{R}_{1} \equiv \mathrm{CH}_{3}, \mathbf{R}_{2} \equiv p-\mathrm{NO}_{2} \mathrm{Ph}, \mathrm{R}_{3} \equiv \mathrm{H}, \mathrm{X} \equiv \mathrm{H} ; \mathbf{1 f}, \mathbf{R}_{1} \equiv \mathrm{CH}_{3}, \mathbf{R}_{2} \equiv p-\mathrm{ClPh}, \mathbf{R}_{3} \equiv \mathrm{H}_{\text {, }}$ $\mathrm{X} \equiv \mathrm{H} ; \mathbf{1 g}, \mathrm{R}_{1} \equiv \mathrm{CH}_{3}, \mathbf{R}_{2} \equiv \mathbf{2}$-naphthyl, $\mathbf{R}_{3} \equiv \mathrm{H}, \mathrm{X} \equiv \mathrm{H} ; \mathbf{1 h}, \mathbf{R}_{1} \equiv \mathrm{CH}_{3}, \mathbf{R}_{2} \equiv \mathbf{P h}, \mathbf{R}_{3} \equiv \mathrm{H}$, $\mathrm{X} \equiv \mathrm{NO}_{2} ; 1 \mathrm{i}, \mathbf{R}_{1} \equiv \mathrm{CH}_{3}, \mathbf{R}_{2} \equiv \mathrm{Ph}, \mathbf{R}_{3} \equiv \mathrm{H}, \mathrm{X} \equiv \mathrm{OCH}_{3} ; \mathbf{1} \mathbf{j}, \mathbf{R}_{1} \equiv \mathbf{P h}, \mathbf{R}_{2} \equiv$ 2-naphthyl, $\mathbf{R}_{3} \equiv$ $H, X \equiv H ; 1 k, R_{1} \equiv P h, R_{2} \equiv P h, R_{3} \equiv H, X \equiv H$.

A brief review of the relevant photochemistry of simple aryl oxiranes will be useful. Aryl oxiranes can undergo photochemical fragmentation reactions in solution to give aryl carbenes and carbonyl compounds [5]. When photolyzed in matrices at $77 \mathrm{~K}$, the oxiranes also give rise to colored species [6] characterized as carbonyl ylides arising from the cleavage of the $\mathrm{C}-\mathrm{C}$ bond in the oxirane ring [7]. Oxiranes are isoelectronic with cyclopropyl anions which are predicted by the Woodward-Hoffman rules [8] to open photochemically to allyl anions in a disrotatory manner. Such a stereoselective ring opening has been observed for the anion produced from cis,trans-2,3-diphenyl-cyclopropanecarbonitrile [9] and has also been documented for aziridines [10], the nitrogen analogues of oxiranes. A similar stereospecific electrocyclic process has been observed when $(Z)$ - and $(E)$ 2,3-diphenyl-oxiranes in ethanol glass at $77 \mathrm{~K}$ undergo photochemical ring opening to two different colored intermediates. Irradiation of these intermediates with visible light at $77 \mathrm{~K}$ regenerates the original oxiranes in a stereospecific manner [7]. 

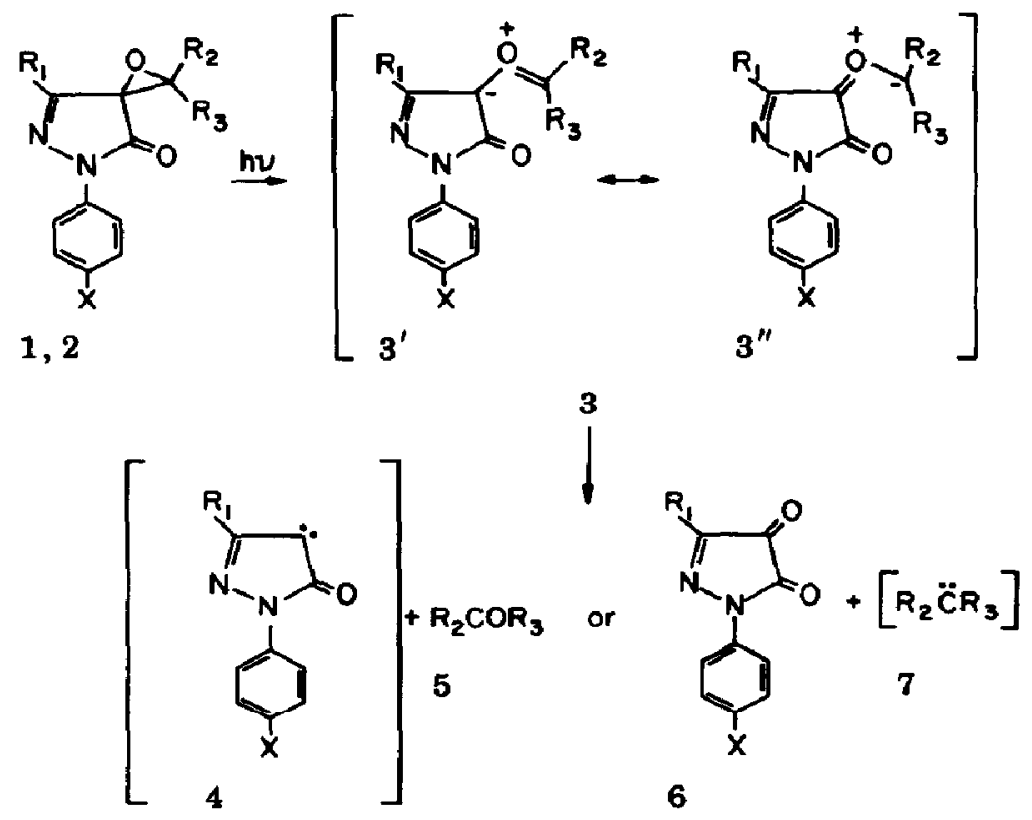

Fig. 2. Photolysis of spirooxiranes 1 and 2.

An ongoing controversy exists regarding the electronic nature of the species designated as carbonyl ylides. Yamaguchi and coworkers [11] conclude from theoretical calculations that a single configuration is insufficient to describe the ground state of this species adequately so that unrestricted Hartree-Fock calculations are required. These workers also describe the carbonyl ylide as significantly diradical in character but indicate that substituted ylides are more accurately represented as closed-shell zwitterions $[11,12]$. Computations carried out by Houk et al. [13] and by Jean and Volatron [14] and Hiberty and Leforstier [15] also indicate that the ylide, if symmetrical, may have appreciable diradical character derived from a reduced gap between the highest occupied and the lowest unoccupied molecular orbitals in such systems. The absorption spectra of the colored materials observed upon photolysis of the aryl oxiranes, however, do not agree with those of known anions [16], cations [16, 17] or radicals [18]. No election spin resonance (ESR) signal is detected in the temperature range $77-140 \mathrm{~K}$, where the colored intermediates are stable, indicating that a triplet diradical is not formed as a stable species [7].

The evidence that carbonyl ylides derived from unsymmetrically substituted species are ionic in character is clearer. Simple valence bond structures such as 3 (Fig. 2) can be used to predict the mode of cleavage of unsymmetrical oxiranes successfully [5]. Thus we would predict that the electronic character of the carbonyl ylide 3 is most accurately represented by structure $3^{\prime}$ and that such systems would fragment to give the heterocyclic carbenes 4 in preference to their aryl counterparts 7 . The validity of generalizations of this type is supported by ab initio self-consistent field 
calculations using STO-3G and 4-31G basis sets and $3 \times 3$ configuration interactions [13].

Carbonyl ylides exhibit marked stability in the ground state. Such ylides have been generated at high temperatures $\left(100-200{ }^{\circ} \mathrm{C}\right)$ and trapped with dipolarophiles to give high yields of [3+2] cycloadducts with no evidence of carbene formation [19 - 21]. Double-irradiation techniques, however, have demonstrated that carbonyl ylides fragment photochemically. Yields of products formed by trapping the resulting carbenes and carbonyl compounds with alkenes increase when visible, in addition to $U V$, radiation is used in the photolysis of oxiranes [22]. Laser flash photolysis experiments using an excimer laser $(\lambda=248 \mathrm{~nm})$ have shown, however, that carbenes are also formed directly from oxiranes without the intermediacy of an ylide [23].

Confirmation of the photochemical formation of carbonyl ylides from oxiranes has been obtained by trapping experiments in which the 1,3 dipolar intermediates generated from 2-aryl-3,3-dicyanooxiranes react with dipolarophiles such as 2,3-dimethyl-2-butene, 2-methylpropene, ethylene and acetylene to give cyclic ethers or with methanol to give acetals [24]. Carbonyl ylides from 2,3-diaryloxiranes have been trapped by electrondeficient alkenes such as dimethyl fumarate, fumaronitrile and methyl acrylate [25].

\section{Experimental details}

\subsection{General}

The synthesis and purification of the oxiranes used in this study have been described elsewhere [2]. $p$-nitrophenyl-diazomethane was prepared from $p$-nitrobenzaldehyde by manganese dioxide oxidation of the corresponding hydrazone [26]. Spectral grade solvents were used without further purification. Low temperature and preparative scale photolyses were carried out in a Rayonet photochemical reactor. Proton magnetic resonance spectra were obtained using a Varian $A-60$ and $T-60$ or a Hitachi-Perkin-Elmer R-20B spectrometer. Mass spectral studies were conducted using a HitachiPerkin-Elmer RME-6E spectrometer or an MS-902 high resolution instrument.

Melting points were determined using a Thomas-Hoover capillary melting point apparatus and are uncorrected. Solutions were concentrated on a Büchi rotating evaporator under vacuum. Eastman chromatogram sheets (silica gel) were used for thin layer chromatography and silica gel 60 (PF 254, Merck) was employed for thick layer separations.

\subsection{Laser flash photolyses}

The excitation sources employed at the Center for Fast Kinetics Research at the University of Texas at Austin were a nitrogen laser $(337 \mathrm{~nm}$; $9 \mathrm{~ns})$ and a neodymium-doped yttrium aluminum garnet system (265 nm; $30 \mathrm{ps)}$ [27]. For each experiment a volume of about $1.5 \mathrm{ml}$ was contained in 
a cuvette through which a slow stream of nitrogen gas (to provide both removal of oxygen and circulation of the sample) was bubbled throughout the experiments. The concentration of the oxirane substrate was chosen so as to give an optical density of about 1 at the excitation wavelength (about $5 \times 10^{-5}-10^{-3} \mathrm{M}$ ). In each case the spectral region $380-720 \mathrm{~nm}$ was examined for transient absorptions. All photolyses were conducted at room temperature.

Experiments at the Radiation Laboratory at Notre Dame [28] were carried out in rectangular quartz cells $(3 \mathrm{~mm} \times 7 \mathrm{~mm})$ using pulses $(337.1 \mathrm{~nm}$; $8 \mathrm{~ns} ; 3 \mathrm{~mJ}$ ) from a Molectron UV -400 nitrogen laser system for excitation. Photolyses were carried out with and without degassing the solutions. The transients were monitored by a kinetic spectrophotometer consisting of an Eimac $150 \mathrm{~W}$ xenon lamp (pulsed), a high intensity Bausch and Lomb monochromator and an RCA 4840 photomultiplier tube. The signal from the photomultiplier tube was terminated via a $93 \Omega$ resistor into a Tektronix transient digitizer, which in turn was interfaced with a multiuser PDP 11/55 computer system that controlled the experiments, processed the data and stored the information. Electromechanical shutters in the paths of exciting and analyzing lights as well as appropriate Corning filters were used to minimize undue exposure of samples to actinic light. The response of the detector system was 1 ns or less. The results of the laser flash photolysis experiments are summarized in Tables $1-3$.

\subsection{Sensitization experiments}

Sensitization experiments were carried out on oxiranes $1 \mathrm{e}, 1 \mathrm{~g}, 1 \mathrm{~h}$ and 2 by laser flash photolyses of benzene solutions $(0.5-2 \mathrm{mM})$ in the presence of benzophenone, acetophenone or $p$-methoxyacetophenone $(0.1-0.3 \mathrm{M})$. In these experiments more than $70 \%$ of the laser photons were absorbed by the aromatic ketones, producing the corresponding triplets (monitored at $530 \mathrm{~nm}$ for benzophenone and $390 \mathrm{~nm}$ for $p$-methoxyacetophenone) which were quenched by the oxiranes. Ylide spectra were observed for oxiranes 1e, $1 \mathrm{~g}$ and 2 but not for $1 \mathrm{~h}$. Sensitization of $1 \mathrm{~h}(0.6 \mathrm{mM})$ by benzophenone $(0.02 \mathrm{M})$ triplets generated in benzene by pulse radiolysis [29] was also attempted. Again the quenching of the triplet was observed, but without the formation of an ylide in any significant amount.

\subsection{Laser flash photolysis of p-nitrophenyldiazomethane}

$p$-nitrophenyldiazomethane [26] in methylene chloride $\left(1.8 \times 10^{-4} \mathrm{M}\right)$ gave a transient with absorption at $\lambda_{\max } \equiv 530 \mathrm{~nm}$ on laser excitation at $337 \mathrm{~nm}$.

2.5. Determination of the ylide spectra of 2-(2-naphthyl)-5-phenyl-7-methyl1-oxa-5,6-diazaspiro[2.5]hept-6-en-4-one (1g) and 2,5-diphenyl-7-methyl-1oxa-5,6-diazaspiro[2.4] hept-6-en-4-one (1d) at $77 \mathrm{~K}$

The spirooxirane $1 \mathrm{~g}$ or $1 \mathrm{~d}(5 \mathrm{mg})$ was dissolved in dry 3-methylpentane $(35 \mathrm{ml})$ in a $100 \mathrm{ml}$ quartz test tube. The tube was sealed with a rubber 
TABLE 1

Transient lifetimes $\tau$ observed upon flash photolysis of pyrazolinone spirooxiranes ${ }^{a, b}$

\begin{tabular}{|c|c|c|c|c|}
\hline \multirow{2}{*}{$\begin{array}{l}\text { Spiro- } \\
\text { oxirane }\end{array}$} & \multicolumn{4}{|c|}{$\tau(\mu s)$ in the following solutions } \\
\hline & Benzene & A cetonitrile & Halocarbon & Alkane \\
\hline $1 \mathbf{a}$ & NSc & NS* & $\mathbf{N S}^{\mathbf{d}}$ & \\
\hline $\mathbf{1 b}$ & NS & NS* & $\mathbf{N S}^{\mathbf{d}}$ & \\
\hline $1 \mathrm{c}$ & $0.34(430 \mathrm{~nm})$ & & & $0.86(410 \mathrm{~nm})^{*}, \mathrm{e}$ \\
\hline $1 d$ & $\begin{array}{l}1.0(505 \mathrm{~nm}) \\
1.2(675 \mathrm{~nm})\end{array}$ & $0.36(610 \mathrm{~nm})^{*}$ & $\begin{array}{l}0.87(640 \mathrm{~nm})^{d} \\
0.88(520 \mathrm{~nm})^{d}\end{array}$ & \\
\hline $1 \mathbf{e}$ & $\begin{array}{r}8.6(550 \mathrm{~nm}) \\
10.3(690 \mathrm{~nm})\end{array}$ & $\begin{array}{l}1.25(510 \mathrm{~nm}) \\
1.11(690 \mathrm{~nm}) \\
\text { "dry" acetonitrilef } \\
2.5(529 \mathrm{~nm}) \text { and } \\
\text { a minor component, } \\
5.4(530 \mathrm{~nm})\end{array}$ & $\begin{array}{c}7.43(540 \mathrm{~nm})^{\mathrm{d}} \\
(680 \mathrm{~nm})\end{array}$ & $7.7(520 \mathrm{~nm})^{*, e}$ \\
\hline $1 \mathrm{f}$ & $1.22(510 \mathrm{~nm})$ & $\begin{array}{l}0.16(660 \mathrm{~nm}) \\
\text { "dry" acetonitriles; } \\
0.45(510 \mathrm{~nm})\end{array}$ & $\begin{array}{l}1.58(520 \mathrm{~nm})^{\mathrm{d}} \\
1.30(660 \mathrm{~nm})^{\mathrm{d}}\end{array}$ & \\
\hline $\mathbf{1 g}$ & $1.6(540 \mathrm{~nm})$ & $0.71(540 \mathrm{~nm})$ & $\begin{array}{l}1.1(540 \mathrm{~nm})^{h} \\
1.6(540 \mathrm{~nm})^{j}\end{array}$ & $0.90(540 \mathrm{~nm})^{\mathrm{i}}$ \\
\hline $1 \mathrm{~h}$ & $\begin{array}{l}1.25(500 \mathrm{~nm})^{\mathrm{f}} \\
1.06(660 \mathrm{~nm})^{\mathrm{f}}\end{array}$ & $0.25(630 \mathrm{~nm})^{f}$ & $\begin{array}{c}1.04(660 \mathrm{~nm})^{d, f} \\
(470 \mathrm{~nm})\end{array}$ & \\
\hline $\mathbf{1 i}$ & $0.97(550 \mathrm{~nm})$ & $<0.01(580 \mathrm{~nm})$ & $1.32(530 \mathrm{~nm})^{\mathrm{d}}$ & $1.12(550 \mathrm{~nm})^{\mathrm{e}, \mathrm{k}}$ \\
\hline
\end{tabular}

$337 \mathrm{~nm}$ excitation except where the asterisk indicates $265 \mathrm{~nm}$.

bThe wavelengths given are not necessarily the band maxima but where the kinetic analysis was performed. Where two bands are noted, the more intense band is given in bold type.

${ }^{\mathrm{C}} \mathrm{NS}$, no usable signal on excitation at 265 or $337 \mathrm{~nm}$.

dIn methylene chloride.

In hexane.

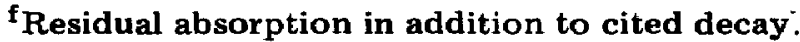

${ }^{g}$ Acetonitrile was dried by refluxing and distilling over $\mathrm{P}_{2} \mathrm{O}_{5}$.

hIn carbon tetrachloride.

iIn cyclohexane.

jIn 1,2-dichloroethane.

${ }^{k} A$ minor faster component was also observed in this case.

septum and purged with nitrogen for $0.5 \mathrm{~h}$. It was then immersed in liquid nitrogen contained in a quartz Dewar and the whole assembly was placed in a Rayonet photochemical reactor equipped with 16 GE G8T5 low pressure mercury lamps. After allowing $0.2 \mathrm{~h}$ for the formation of the 3-methylpentane glass, the lamps were turned on for $3 \mathrm{~min}$. The tube was then rapidly transferred to a similar quartz Dewar positioned in the sample compartment of a Cary 17 UV-visible spectrophotometer. The Dewar had already been filled with liquid nitrogen, care being taken that the liquid nitrogen level was 
TABLE 2

Transient lifetimes $\tau$ observed upon flash photolysis of pyrazole blue oxide (2) in a variety of solvents at room temperature ${ }^{a}$

\begin{tabular}{ll}
\hline Solvent & $\tau(\mu \mathrm{s})$ \\
\hline Perfluoro-n-hexane & 0.11 \\
Cyclohexane & 0.17 \\
Carbon tetrachloride & 0.30 \\
Tetrahydrofuran & 0.44 \\
Ethyl acetate & 0.48 \\
Benzene & 0.50 \\
Acetonitrile & 0.65 \\
tert-butyl alcohol & 0.74 \\
2-propanol & 0.77 \\
Acetone & 0.79 \\
1,2-dichloroethane & 0.83 \\
Ethanol & 0.89 \\
Methanol & 2.9 \\
2,2,2-trifluoroethanol & 7.9 \\
\hline
\end{tabular}

a $337 \mathrm{~nm}$ excitation; transient monitored at or near $430 \mathrm{~nm}$.

\section{TABLE 3}

Bimolecular rate constants for the quenching of the transients from pyrazolinone spirooxiranes by protic solvents and alkenes

\begin{tabular}{|c|c|c|c|}
\hline Spirooxirane & Solvent & Quencher ${ }^{\mathrm{a}}$ & $k_{\mathrm{v}}\left(\mathrm{M}^{-1} \mathrm{~s}^{-1}\right)$ \\
\hline $1 \mathbf{e}$ & Benzene & $\mathrm{CH}_{3} \mathrm{OH}$ & $4.1 \times 10^{7}$ \\
\hline $1 \mathbf{e}$ & Acetonitrile & $\mathrm{CH}_{3} \mathrm{OH}$ & $3.4 \times 10^{7}$ \\
\hline 1e & Methylene chloride & $\mathrm{CH}_{3} \mathrm{OH}$ & $4.4 \times 10^{7}$ \\
\hline 1e & Methylene chloride & $\mathrm{H}_{2} \mathrm{O}$ & $1 \times 10^{6}$ \\
\hline 1e & Benzene & $\left(\mathrm{CH}_{3}\right)_{2} \mathrm{CC}\left(\mathrm{CH}_{3}\right)_{2}$ & $4.0 \times 10^{5}$ \\
\hline $1 f$ & Benzene & $\mathrm{CH}_{3} \mathrm{OH}$ & $4.0 \times 10^{8}$ \\
\hline $1 \mathrm{~g}$ & Benzene & $\left(\mathrm{CH}_{3}\right)_{3} \mathrm{COH}$ & $2.2 \times 10^{7}$ \\
\hline $1 \mathrm{~g}$ & Benzene & $\left(\mathrm{CH}_{3}\right)_{2} \mathrm{CHOH}$ & $1.8 \times 10^{8}$ \\
\hline $1 \mathrm{~g}$ & Benzene & $\mathrm{CH}_{3} \mathrm{CH}_{2} \mathrm{OH}$ & $2.1 \times 10^{8}$ \\
\hline $1 \mathrm{~g}$ & Benzene & $\mathrm{CH}_{3} \mathrm{OH}$ & $5.6 \times 10^{8}$ \\
\hline $1 \mathrm{~g}$ & Benzene & $\mathrm{CF}_{3} \mathrm{CH}_{2} \mathrm{OH}$ & $1.3 \times 10^{8}$ \\
\hline $1 \mathrm{~g}$ & Benzene & $\left(\mathrm{CH}_{3}\right)_{2} \mathrm{CC}\left(\mathrm{CH}_{3}\right)_{2}$ & $4.0 \times 10^{6}$ \\
\hline $1 \mathrm{i}$ & Benzene & $\mathrm{CH}_{3} \mathrm{OH}$ & $5.6 \times 10^{8}$ \\
\hline 2 & Benzene & $\left(\mathrm{CH}_{3}\right)_{2} \mathrm{CC}\left(\mathrm{CH}_{3}\right)_{2}$ & No quenching \\
\hline
\end{tabular}

${ }^{a}$ Range of quencher concentrations, $3 \times 10^{-3}-2.0 \mathrm{M}$.

below the radiation path of the spectrophotometer. A $1 \mathrm{~cm}$ quartz cell containing 3-methylpentane was used as the reference. Final instrument adjustments were made as rapidly as possible and the spectrum was recorded at a rate of $2 \mathrm{~nm} \mathrm{~s}^{-1}$ from 800 to $400 \mathrm{~nm}$. The maximum wavelengths were as follows: $1 \mathrm{~d}, \lambda_{\max }=505$ and $675 \mathrm{~nm} ; 1 \mathrm{~g}, \lambda_{\max }=530$ and $728 \mathrm{~nm}$. 
2.6. Irradiation of spirooxiranes $\mathrm{ld}, \mathrm{lg}, \mathrm{lj}$ and $\mathrm{lk}$ in protic solvents

The experiments, the results of which are summarized in Table 4, were performed in the following way. The spirooxirane $(0.609 \mathrm{mmol})$ in the solvent $(45 \mathrm{ml})$ was placed in a test tube (quartz for $1 \mathrm{~d}$ and $1 \mathrm{k}$, Pyrex for $1 \mathrm{~g}$ and $1 \mathrm{j}$ ). The test tube was sealed with a rubber septum and purged with nitrogen for $0.5 \mathrm{~h}$. It was then placed in a Rayonet photochemical reactor equipped with a magnetic stirrer. The stirred suspension was irradiated (at $254 \mathrm{~nm}$ for $1 \mathrm{~d}$ and $1 \mathrm{k}$ and at $350 \mathrm{~nm}$ for $1 \mathrm{~g}$ and $1 \mathrm{j}$ ). The methanol was then evaporated under reduced pressure and the residue was triturated with ether $(4 \mathrm{ml})$. The white precipitate was filtered off, washed with ether (about $3 \mathrm{ml}$ ) and dried in vacuo for $6 \mathrm{~h}$. 3-methyl-1-phenyl-4,5-dihydroxypyrazole (10a) (melting point, $190-193{ }^{\circ} \mathrm{C}$, with decomposition (published value, $\left.190{ }^{\circ} \mathrm{C}[30]\right)$; nuclear magnetic resonance (NMR) spectrum ( $d_{6}$-dimethyl sulfoxide) $(\delta(\mathrm{ppm})), 2.1$ (singlet $(\mathrm{s}) ; 3 \mathrm{H}$; methyl hydrogen), 7.14 - 7.41 (multiplet (m); $5 \mathrm{H}$; phenyl hydrogen), 7.22 (broad peak (br); $1 \mathrm{H}$; hydroxy hydrogen), 7.81 (br; $1 \mathrm{H}$; hydroxy hydrogen); $m / e 190\left(M^{+}\right)$) was isolated from the photolysis of $1 \mathrm{~d}$ and $1 \mathrm{~g}$. 1,3-diphen yl-4,5-dihydroxypyrazole (10b) (melting point, $200-203{ }^{\circ} \mathrm{C}$, with decomposition (published value, 200 $\left.208{ }^{\circ} \mathrm{C}[31]\right) ; m / e 252\left(M^{+}\right)$) was obtained from $1 \mathrm{j}$ and $1 \mathrm{k}$.

\section{TABLE 4}

Products from the irradiation of pyrazolinone spirooxiranes in protic solvents

\begin{tabular}{|c|c|c|c|c|}
\hline $\begin{array}{l}\text { Spiro- } \\
\text { oxirane }\end{array}$ & Solvent & $\begin{array}{l}\text { Time } \\
\text { (h) }\end{array}$ & $\begin{array}{l}\text { Pyrazole } \\
\text { (yield (\%)) }\end{array}$ & $\begin{array}{l}\text { A cetal (detected } \\
\text { by } N M R^{\mathrm{a}} \text { ) }\end{array}$ \\
\hline 1d & Methanol & 4 & $10 \mathrm{a}(65)$ & $\mathbf{9 a}$ \\
\hline $1 \mathrm{~g}$ & Methanol & 24 & $10 \mathbf{a}(81)$ & $9 b$ \\
\hline $1 \mathrm{~g}$ & Methanol-3-methylpentane $(1: 9)$ & 24 & $10 \mathrm{a}(77)$ & $9 b$ \\
\hline $1 \mathrm{~g}$ & Methanol-acetone $(1: 4)$ & 24 & $10 \mathrm{a}(48)$ & $9 \mathbf{b}$ \\
\hline $1 \mathrm{~g}$ & tert-butyl alcohol & 24 & 10 a (54) & - \\
\hline $\mathbf{1 j}$ & Methanol & 24 & $10 \mathrm{~b}(67)$ & $\mathbf{9 b}$ \\
\hline $1 \mathbf{k}$ & Methanol & 4 & $10 b(63)$ & $9 \mathbf{a}$ \\
\hline
\end{tabular}

aNMR, nuclear magnetic resonance.

The ether wash of the residue from the photolysis mixture was evaporated under reduced pressure and the material that remained was examined using NMR. 2-naphthaldehyde dimethyl acetal (9b) was detected in the mixture obtained from $1 \mathrm{~g}$ and $1 \mathrm{j}$ of bands of $\delta(\mathrm{ppm})$ (solvent, $\mathrm{CDCl}_{3}$ ), 3.32 (s; $6 \mathrm{H}$; methoxy hydrogen), $5.50\left(\mathrm{~s} ; 1 \mathrm{H} ; \mathrm{CH}\left(\mathrm{OCH}_{3}\right)_{2}\right), 7.72-7.80$ ( $\mathrm{m} ; 7 \mathrm{H}$; naphthyl hydrogen). These bands were enhanced by the addition of an authentic sample of 2-naphthaldehyde dimethyl acetal prepared by dissolving the aldehyde $(0.5 \mathrm{~g}, 0.003 \mathrm{~mol})$ in dry methanol $(25 \mathrm{ml})$, bubbling in dry $\mathrm{HCl}$ for $3 \mathrm{~s}$ and allowing the flask to stand at room temperature for $1 \mathrm{~h}$. Evaporation of the methanol under reduced pressure in an apparatus protected from moisture gave a clear oil $(0.56 \mathrm{~g})$ consisting of a mixture of $9 \mathrm{~b}$ and 2-naphthaldehyde $(\delta, 9.70 \mathrm{ppm} ; \mathrm{s}$; aldehyde hydrogen). Benzal- 
dehyde dimethyl acetal (9a) was detected in the photolysis mixtures from 1d and $1 \mathbf{k}$ in a similar way.

2.7. General procedure for the irradiation of the spirooxiranes $I d, I g, I h, I j$, $1 k$ and 2 in the presence of dipolarophiles

The spirooxirane $(0.610 \mathrm{mmol})$ was suspended in the pure dry alkene or a mixture of the alkene and a solvent $(30 \mathrm{ml})$ and placed in a $100 \mathrm{ml}$ Pyrex or quartz test tube. The tube was sealed with a rubber septum and purged with nitrogen for $0.5 \mathrm{~h}$. It was then placed in a Rayonet photochemical reactor equipped with a magnetic stirrer. The stirred mixture was irradiated for $24 \mathrm{~h}$ (at $350 \mathrm{~nm}$ for the 2-(2-naphthyl) oxiranes and at $254 \mathrm{~nm}$ for the 2-phenyl oxiranes). At the end of this period the contents were transferred to a flask and the solvents were removed under reduced pressure. In all cases the residue proved to be a dark brown tarry material. In the case of the 2-(2-naphthyl)-substituted oxiranes, 2-naphthaldehyde in yields of up to $98 \%$ proved to be the only isolable component (silica gel preparative layer plates were used with chloroform or 1:1 benzene:petroleum ether as eluants). Although benzaldehyde was not isolated in the case of the 2-phenylsubstituted oxiranes, its presence was indicated by a singlet at $\delta=10.00 \mathrm{ppm}$ (aldehyde hydrogen) in the NMR spectrum of the residue. In the case of pyrazole blue oxide (2), 3-methyl-1-phenyl-2-pyrazolin-4,5-dione [32] was detected by thin layer chromatography (silica; benzene eluant). No products resulting from trapping of either the carbonyl ylide 3 or the heterocyclic carbene 4 that should have resulted from the elimination of the aryl aldehyde could be isolated from the reaction mixtures. Table 5 lists the oxiranes and the dipolarophiles used in these experiments.

\section{Results and discussion}

Upon laser flash photolysis, spirooxiranes 1d - 1i, all of which are substituted by an aryl group on the oxirane ring, form transients that absorb in the region between 500 and $720 \mathrm{~nm}$. The first-order decay lifetimes for the transients derived from 1c - 1e in several solvents are shown in Table 1. For most of these compounds, weak signals resulted in poor spectra making it difficult to extract precise values of $\lambda_{\max }$ of the absorption bands. It was necessary to average several decay curves for each half-life determination.

The assignment of ylide structures 3 to the transients observed is reasonable in the light of the rough correspondence of their spectra (with two absorption bands, one in the region of $500-580 \mathrm{~nm}$ and one at wavelengths longer than $650 \mathrm{~nm}$ ) to previously reported spectra $[6,7]$ and the spectra recorded in a 3 -methylpentane glass at $77 \mathrm{~K}$ for oxirane $1 \mathrm{~d}\left(\lambda_{\max }\right.$, 505 and $675 \mathrm{~nm})$ and for $1 \mathrm{~g}\left(\lambda_{\max }, 530\right.$ and $\left.728 \mathrm{~nm}\right)$.

In general the spectrum of each transient did not vary with time after the laser pulse (or conversely the decay rate was the same throughout the spectrum) and a first-order decay to absorbance close to zero was observed. 
TABLE 5

Irradiation of the spirooxiranes $1 \mathrm{~d}, 1 \mathrm{~g}, 1 \mathrm{~h}, 1 \mathrm{j}, 1 \mathrm{k}$ and 2 : presence of dipolarophiles

\begin{tabular}{|c|c|c|}
\hline Spirooxirane & Dipolarophile & Solvent \\
\hline 1d & 2,3-dimethyl-2-butene & None \\
\hline $1 d$ & Cyclopentene & None \\
\hline 1d & 2-methyl-2-butene & None \\
\hline $1 \mathrm{~g}$ & 2-methyl-2-butene & None \\
\hline $1 \mathrm{~g}$ & 2-methyl-2-butene & $\mathrm{CH}_{3} \mathrm{CN}$ \\
\hline $1 \mathrm{~g}$ & Fumaronitrile & $\mathrm{CH}_{3} \mathrm{CN}$ \\
\hline $1 \mathrm{~g}$ & Fumaronitrile & PhH \\
\hline 1g & trans-stilbene & $\mathrm{CH}_{3} \mathrm{CN}$ \\
\hline 1g & Dimethyl acetylenedicarboxylate & None \\
\hline $\mathbf{1 g}$ & Dimethyl maleate & None \\
\hline $1 \mathrm{~g}$ & Ethyl trifluoroacetate & None \\
\hline 1h & $(E)-\mathbf{2}$-butene & $\mathrm{CH}_{3} \mathrm{CN}$ \\
\hline $\mathbf{1 j}$ & 2-methyl-2-butene & None \\
\hline $\mathbf{1 j}$ & Cyclohexene & None \\
\hline $\mathbf{1 j}$ & 2,3-dimethyl-2-butene & None \\
\hline $\mathbf{1} \mathbf{k}$ & 2,3-dimethyl-2-butene & None \\
\hline 2 & 2-methyl-2-butene & None \\
\hline 2 & Cyclopentene & None \\
\hline 2 & Cyclohexene & None \\
\hline
\end{tabular}

The observed half-lives for decay of these transients are of the order of $1 \mu \mathrm{s}$ (Table 1), except for the transient from 1e which will be discussed separately later. Except in a few cases (see later), the results do not show any significant variation in lifetime with structure or substitution pattern among the arylsubstituted oxiranes.

In contrast with the compounds with aryl substituents on the oxirane ring, no transient absorption signals were detected in benzene, methylene chloride or acetonitrile for spirooxiranes $1 \mathrm{a}$ and $\mathbf{1 b}$ with methyl substitution on the oxirane and at $\mathrm{C}(3)$ of the pyrazolinone ring (Table 1 ). The compound with methyl substitution on the oxirane ring but bearing a phenyl group at $C(3)$ of the pyrazoline ring (oxirane 1c) did give a transient with $\lambda_{\max }=430 \mathrm{~nm}(\tau=0.34 \mu \mathrm{s})$ in benzene and $\lambda_{\max }=430 \mathrm{~nm}(\tau=0.86 \mu \mathrm{s})$ in hexane. No transient could be observed for this oxirane system in acetonitrile or methylene chloride.

Two of the oxiranes, $1 \mathrm{c}$ in hexane and $1 \mathrm{~h}$ in benzene and acetonitrile, give rise to a second longer-lived species as well as the transients listed in Table 1. The longer-lived species from $1 \mathrm{c}$ had $\lambda_{\max } \approx 410 \mathrm{~nm}$, while that from $1 \mathrm{~h}$ had $\lambda_{\max } \leqslant 360 \mathrm{~nm}$ and decayed very slowly or not at all over a period of about $200 \mu$ s.

Three of the oxiranes that gave well-defined spectra $(1 \mathrm{e}, 1 \mathrm{~g}$ and 2$)$ were studied in detail. The absorption spectra of the transients generated by laser flash photolyses of these oxiranes in benzene at room temperature exhibit 

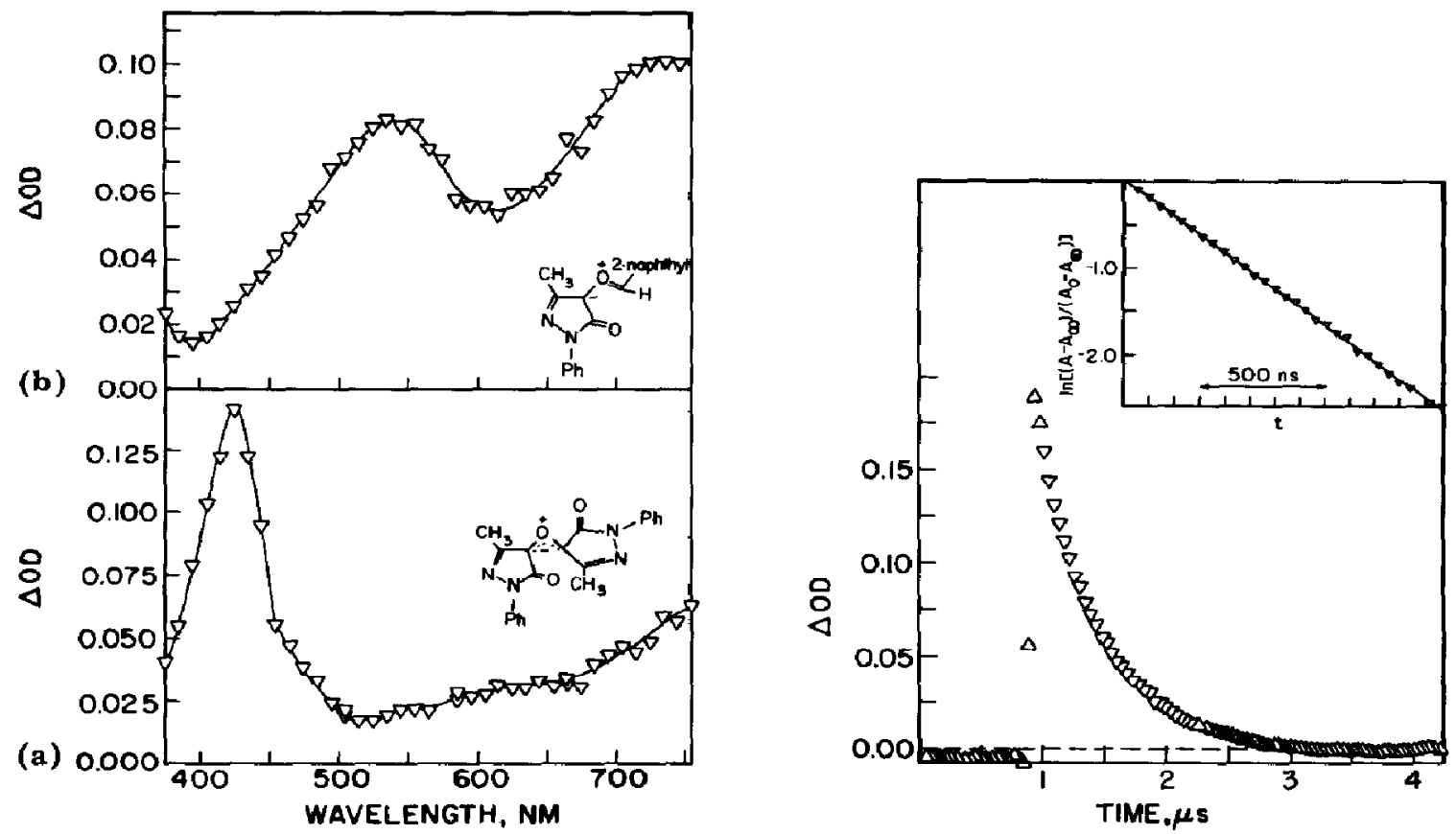

Fig. 3. Absorption spectra of transient ylides generated by $337.1 \mathrm{~nm}$ laser flash photolysis of (a) oxirane $2(4 \mathrm{mM})$ in benzene and (b) oxirane $1 \mathrm{~g}(5 \mathrm{mM})$ plus acetophenone $(0.17 \mathrm{M})$ in benzene.

Fig. 4. Decay profile of the ylide from oxirane 2 in benzene generated by $337.1 \mathrm{~nm}$ laser flash photolysis and monitored at $430 \mathrm{~nm}$. The inset shows the plot of the kinetic data according to the integrated equation for first-order decay.

two maxima (around 540 and $700-740 \mathrm{~nm}$ for $1 \mathrm{e}$ and $1 \mathrm{~g}$, and at 425 and $765 \mathrm{~nm}$ for 2 (Fig. 3)). The observed first-order lifetimes $\tau$ in the two spectral regions are identical within experimental error, indicating that the same species is responsible for the two maxima. A representative kinetic trace for the decay of the ylide derived from oxirane 2 in benzene and the kinetic fit of the data are given in Fig. 4. The ylide 3c has the shortest lifetime $(0.34 \mu \mathrm{s}$ (Table 1 )) under these conditions, while ylide $3 e$ has the longest lifetime (10 $\mu$ s (Table 1)).

Some rationalization of the differences observed in the lifetimes of these ylides can be offered. For 1d-1i, disrotatory opening [8] of the oxirane ring gives intermediates in which a hydrogen atom faces the pyrazolinone ring in the planar ylide. In contrast, ylide $3 c$, in which $R_{2}$ and $R_{3}$ are methyl groups (Fig. 2) and the ylide derived from 2 , in which a second pyrazolinone ring flanks the oxirane, would be expected to be destabilized by steric interference of these larger groups with the heterocyclic ring. Ylide 3c also lacks the stabilization that delocalization of charge to an aryl ring provides. The particular stability of the ylide from $1 \mathrm{e}$ can be attributed to the added importance of the canonical structure $3 e^{\prime \prime}$ (Fig. 2) when the possibility of delocalization of negative charge to the $p$-nitro group exists. 


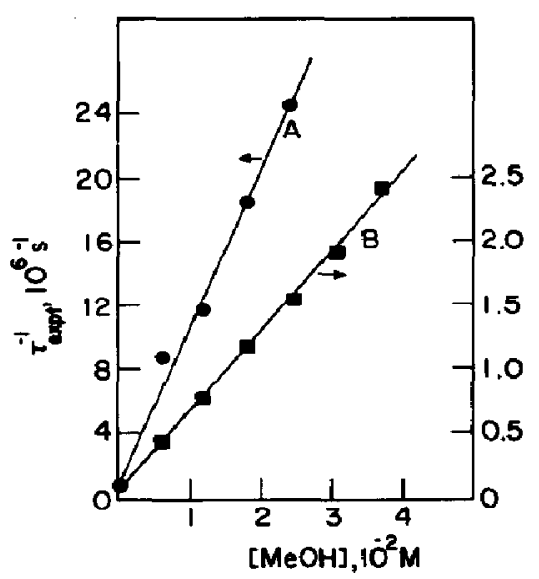

Fig. 5. Plots of the reciprocal of the observed ylide lifetime $\tau_{\text {expt }}$ as a function of the methanol concentration in benzene: curve $A$, oxirane precursor 1 h; curve $B$, oxirane precursor 1 e.

The lifetimes, but not the yields, of ylides derived from 1e, 1f, $1 \mathrm{~g}$ and 1i decrease in the presence of millimolar amounts of methanol in benzene. Figure 5 shows plots based on

$\tau_{\text {expt }}^{-1}=\tau_{0}^{-1}+k_{\mathrm{q}}[\mathrm{MeOH}]$

where $\tau_{\text {expt }}$ is the observed lifetime at methanol concentration [ $\left.\mathrm{MeOH}\right]$. In benzene the rate constant for quenching of ylide $3 \mathrm{~g}$ is $5.6 \times 10^{8} \mathrm{M}^{-1} \mathrm{~s}^{-1}$ while that for $3 \mathrm{e}$ is $4.1 \times 10^{7} \mathrm{M}^{-1} \mathrm{~s}^{-1}$. Quenching of ylide $3 \mathrm{~g}$ also occurs at diminished rates with ethanol, 2,2,2-trifluoroethanol, isopropyl and tertbutyl alcohol (Table 3 ).

The stability of carbonyl ylides in the ground state [19-21] leads us to postulate that, in the absence of a trapping reagent or radiaticn leading to further fragmentation of the ylide to carbene and carbonyl compounds [22], the ylide decays by ring closure to the spirooxirane $[7,19]$.

The 1,3 dipolar nature of ylides 3 leads us to expect that the ylide lifetime might be affected by solvent polarity. The experimental data in Table 1 do not show such a clear cut effect on the lifetimes of ylides derived from oxiranes 1 as has been previously noted [23]. Especially noticeable are the short lifetimes in acetonitrile which are probably attributable to dissolved water in that solvent. When the acetonitrile was dried rigorously, the lifetimes increased (see Table 1, 1e and 1f).

In contrast with these results, the lifetime of the transient formed on photolysis of oxirane 2 increases with solvent polarity (Table 2) and the species is not quenched by protic solvents. A similar effect of solvent polarity on the lifetime of a carbonyl ylide has been observed for the epoxide of 9-p-nitrobenzylidenefluorene [23]. In this case, as with 2, the lifetimes of the intermediate increase in going from cyclohexane to benzene to the protic solvents methanol and ethanol. Clearly such effects are not observable for ylides such as 3 that react with alcohols. 
The structural features that lead to the reaction of a carbonyl ylide with a protic and nucleophilic solvent are not easily defined. Experiments were carried out with oxiranes $1 \mathrm{~d}, 1 \mathrm{~g}, 1 \mathrm{j}$ and $1 \mathrm{k}$ to discover the nature of the reaction. Steady state photolyses of these oxiranes in methanol led to the isolation of 3-methyl-1-phenyl-4,5-dihydroxypyrazole $\left(10 a, R_{1} \equiv \mathrm{CH}_{3}\right)$ [30] from oxiranes $1 \mathrm{~d}$ and $1 \mathrm{~g}$, and 1,3-diphenyl-4,5-dihydroxypyrazole (10b, $R_{1}=P h[31]$ ) from $1 \mathrm{~g}$ and $1 k$ (Fig. 6).

Oxiranes $1 \mathrm{~g}$ and $1 \mathrm{j}$ also gave 2-naphthaldehyde dimethylacetal $(9 \mathrm{~b}$, $R_{2} \equiv 2$-naphthyl), while benzaldehyde dimethyl acetal $\left(9 a, R_{2} \equiv P h\right)$ was observed for oxiranes 1d and 1k (Table 4). Previous experience with carbonyl ylides in methanol [24] led us to postulate that these products arise by trapping of the intermediate ylides 3 by the solvent to give acetals 8 that undergo transacetalization reactions in excess solvent. No bands for 2(hydroxymethyl)naphthalene or benzyl alcohol were seen in the NMR spectra of product mixtures from the photolysis. Thus no products to be expected from the trapping of ylide 3 in the alternative polarization (Fig. 2, $\left.3^{\prime \prime}\right)$ were found. These results confirm our contention that ylides correctly represented as $3^{\prime}$ form when oxiranes 1 open and are consistent with the quenching of the transient species seen in the laser photolyses of oxiranes 1e, 1f, $1 \mathrm{~g}$ and $1 \mathrm{i}$ (Table 3).

The ylide from oxirane 2 also differs from the ylides generated from $1 e$ and $1 \mathrm{~g}$ in not being quenched by 2,3-dimethyl-2-butene. Quenching rate constants of $4.0 \times 10^{5} \mathrm{M}^{-1} \mathrm{~s}^{-1}$ for ylide $3 \mathrm{e}$ and $4.0 \times 10^{6} \mathrm{M}^{-1} \mathrm{~s}^{-1}$ for $3 \mathrm{~g}$ were obtained with the alkene (Table 3 ). Thus both of these ylides react about 200 times faster with methanol than with the alkene. Experiments [23] with the ylides derived from the epoxide of 9-p-nitrobenzylidenefluorene and from trans-2-p-nitrophenyl-3-phenyloxirane with electron-poor alkenes have given similar quenching rate constants. The photochemically generated ylide from the first oxirane is quenched by dimethyl acetylenedicarboxylate (DMAD) $\left(k_{\mathrm{q}} \approx 2 \times 10^{7} \mathrm{M}^{-1} \mathrm{~s}^{-1}\right)$ and dimethyl maleate $(\mathrm{DMM})\left(k_{\mathrm{q}} \approx 2 \times\right.$

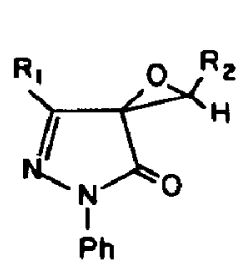

1d, $1 \mathrm{~g}, 1 \mathrm{j}, 1 \mathrm{k}$

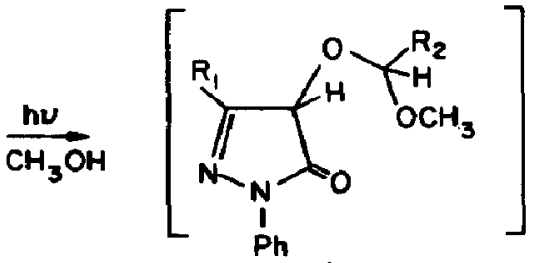

8<smiles>[14CH3]O</smiles><smiles></smiles><smiles>C=C=C(C)OC(=O)c1ccccc1</smiles>

10

Fig. 6. Photolysis of spirooxiranes $1 \mathrm{~d}, 1 \mathrm{~g}, 1 \mathrm{j}$ and $1 \mathrm{k}$ in methanol. 
$\left.10^{6} \mathrm{M}^{-1} \mathrm{~s}^{-1}\right)$, while the rates for the second oxirane are higher $\left(k_{\mathrm{q}}(\mathrm{DMAD}) \approx\right.$ $\left.6 \times 10^{8} \mathrm{M}^{-1} \mathrm{~s}^{-1} ; k_{\mathrm{q}}(\mathrm{DMM}) \approx 9 \times 10^{7} \mathrm{M}^{-1} \mathrm{~s}^{-1}\right)[23]$.

Huisgen [19] has reported values of $1.3 \times 10^{6} \mathrm{M}^{-1} \mathrm{~s}^{-1}$ and $1.0 \times 10^{5}$ $M^{-1} \mathrm{~s}^{-1}$ for the cycloaddition of the ylide generated thermally from trans2,3-dicyano-2,3-diphenyloxirane to dimethyl fumarate and dimethyl maleate respectively. In contrast with the results of Huisgen [19] and other workers $[24,25]$ where tetrahydrofurans which are products of the cycloaddition of carbonyl ylides to alkenes can be isolated, steady state photolyses of a variety of oxiranes 1 in the presence of either electron-rich or electron-poor dipolarophiles did not give any isolable cycloaddition products (Table 5). Carbonyl ylides that have been successfully trapped on a preparative scale, such as the ylide from 2,2-dicyano-3-(2-naphthyl)oxirane [24], have a longer lifetime $(42 \mu \mathrm{s})$ [33] than the ylides from the pyrazolinone spirooxiranes (about $1 \mu \mathrm{s}$ ). The exact nature of the interaction that is responsible for the quenching of ylides 3 by the alkene is not clear.

Ylides 3 should cleave preferentially, as anticipated in non-protic solvents, to give aryl aldehydes and a heterocyclic fragment 4 (Fig. 2). We have not been successful in cleanly trapping the heterocyclic species with alkenes even when $1 \mathrm{~g}$ is irradiated in neat 2-methyl-2-butene at $254 \mathrm{~nm}$. However, 2-naphthaldehyde is isolated in $98 \%$ yield. In contrast, the heterocyclic carbene of analogous structure generated by photolysis of 3-diazo1 -methyl-oxindole is intercepted by alkenes [34]. Attempts to characterize the heterocyclic fragment from the cleavage of ylide 3 continue.

The nature of the excited state that gives rise to the ylides is of interest. A singlet state, with or without the intermediacy of a very short-lived triplet, is suggested by the observation that the yields of ylides from $1 \mathrm{~g}$ and 2 are the same under both air and nitrogen. Laser flash photolysis experiments on benzene solutions of oxiranes $1 \mathrm{e}, 1 \mathrm{~g}, 1 \mathrm{~h}$ and 2 in the presence of benzophenone and $p$-methoxyacetophenone indicate that the ketone triplets are quenched by the oxiranes. At the same time, spectral absorptions attributable to the ylides of oxiranes $2,1 \mathrm{e}$ and $1 \mathrm{~g}$ (monitored at their respective maxima) were observed with magnitudes much enhanced relative to that expected from the fractional absorption (about 30\%) of the laser photons by the oxiranes themselves. This result suggests that in the case of $1 \mathrm{e}, 1 \mathrm{~g}$ and 2 ylides can also be formed by way of the triplet state. With $p$-methoxyacetophenone as the triplet donor, the triplet-mediated formation of ylides is also clearly indicated by a relatively slow growth of a component of the ylide spectrum on the same time scale as the decay of the ketone triplet.

No ylide formation from $1 \mathrm{~h}$ was observed when benzophenone was flash photolyzed in its presence, even though the benzophenone triplet produced in this experiment, and also by pulse radiolysis, is quenched by the oxirane. In this case, then, the ylide clearly arises from the singlet state.

The ylide from oxirane 1e has a longer lifetime (about $10 \mu \mathrm{s}$ in benzene) than any of the other transients characterized as ylides. In an experiment to check whether the long-lived intermediate observed in the photolysis of spirooxirane $1 \mathrm{e}$ is $p$-nitrophenylmethylene $(7 \mathrm{e})$, the carbene that would form 
by the alternative cleavage of ylide 3a (Fig. 2), p-nitrophenyldiazomethane [26] was photolyzed and the transient was recorded at $\lambda_{\max }=530 \mathrm{~nm}$. Triplet $p$-nitrophenylmethylene has been detected by ESR during the photolysis of this diazo compound in a matrix at $77 \mathrm{~K}$ [35] but an electronic spectrum has not been previously reported. The closest model in the literature for this species is the spectrum of the diarylmethylene $p$-nitrophenylphenylmethylene, which absorbs at 265,370 and $555 \mathrm{~nm}$ [18]. While the transient observed when spirooxirane $1 \mathrm{e}$ is photolyzed also absorbs at a similar wavelength $(540 \mathrm{~nm})$, there are differences between the transients generated from the diazo compound and the oxirane. For example, the band at $540 \mathrm{~nm}$ for the transient from 1e is accompanied by a second band at $680 \mathrm{~nm}$ that decays with the same half-life. There is also no detectable formation of 3-methyl-1-phenyl-2-pyrazolin-4,5-dione (6e) [32] (at $\lambda_{\max }=463 \mathrm{~nm}$ ) from the transient absorption spectrum. Dione $6 \mathrm{e}$ would be predicted to be a product if cleavage of ylide 3e occurred to give $p$-nitrophenylmethylene (7e). The absorption of the transient obtained from the diazo compound decays bimolecularly with a half-life dependent on the laser intensity, while the transient from 1e exhibits only first-order decay (or two consecutive firstorder decays). Finally, the transient from 1e reacts with 2,3-dimethyl2 -butene more rapidly than does the transient obtained from the diazo compound.

\section{Summarizing remarks}

Photolyses of a series of pyrazolinone spirooxiranes give rise to transients having absorption spectra in the visible region and lifetimes of the order of $0.3-11 \mu \mathrm{s}$ in benzene at room temperature. Sensitization experiments indicate that the intermediates may arise from a triplet as well as a singlet excited state. The transients from a number of unsymmetrical oxiranes 1 are quenched by protic solvents and by alkenes while that from the symmetrical oxirane 2 is not. Preparative scale photolyses of some oxiranes 1 in methanol give products consistent with the assignment of the structure of the transient as a carbonyl ylide incorporating the pyrazolinone ring.

\section{Acknowledgments}

This work was supported in part by the National Science Foundation (M.A.F. and G.W.G.) and by the Office of Basic Energy Sciences of the Department of Energy. The work at Austin was also generously supported by the Robert $A$. Welch Foundation. Flash photolysis experiments were conducted at the Radiation Laboratory at Notre Dame and at the Center for Fast Kinetics Research which is supported by the National Institutes of Health and by the University of Texas at Austin. This is Document NDRL2379 from the Notre Dame Radiation Laboratory. 


\section{References}

1 S. N. Ē̄e, C. J. Tien, A. Dlesk, B. E. Potter and B. K. Eagleson, J. Chem. Soc., Chem. Commun., (1972) 682 .

2 S. N. Ege, A. D. Adams, E. J. Gess, K. S. Ragone, B. J. Kober, M. B. Lampert, P. Umrigar, D. C. Lankin and G. W. Griffin, J. Chem. Soc., Perkin Trans. I, to be published.

3 R. J. Baker, D. C. Lankin, P. Umrigar, G. W. Griffin, S. N. Eḡe, K. S. Ragone and L. M. Trefonas, J. Heterocycl. Chem., to be published.

4 S. N. Eḡe, E. J. Gess, A. Thomas, P. Umrigar, G. W. Griffin, P. K. Das, A. M. Trozzolo and T. M. Leslie, J. Chem. Soc., Chem. Commun., (1980) 1263.

5 G. W. Griffin, Angew. Chem., Int. Edn. Engl, 10 (1971) 537.

6 R. S. Becker, R. O. Bost, J. Kolc, N. R. Bertoniere, R. L. Smith and G. W. Griffin, J. Am. Chem. Soc., 92 (1970) 1302.

7 T. Do-Minh, A. M. Trozzolo and G. W. Griffin, J. Am. Chem. Soc., 92 (1970) 1402.

8 R. B. Woodward and R. Hoffmann, Angew. Chem., Int. Edn. Engl., 8 (1969) 781.

R. Hoffman, J. Am. Chem. Soc., 90 (1968) 1475.

9 M. A. Fox, J. Am. Chem. Soc., 101 (1979) 4008.

10 R. Huisgen, W. Scheer and H. Huber, J. Am. Chem. Soc., 89 (1967) 1753.

H. Hermann, R. Huisgen and H. Mader, J. Am. Chem. Soc., 93 (1971) 1779.

11 K. Yamaguchi and T. Fueno, Chem. Phys. Lett., 22 (1973) 471.

K. Yamaguchi, Chem. Phys. Lett., 33 (1975) 330.

12 K. Yamaguchi, T. Fueno, A. Nishio and S. Yabushita, Chem. Lett., (1977) 1479.

13 K. N. Houk, N. G. Rondan, C. Santiago, C. J. Gallo, R. W. Gandour and G. W. Griffin, J. Am. Chem. Soc., 102 (1980) 1504.

14 Y. Jean and F. Volatron, Chem. Phys. Lett., 83 (1981) 91.

15 P. C. Hiberty and C. Leforstier, J. Am. Chem. Soc., 100 (1978) 2012.

16 S. F. Mason, Q. Rev., Chem. Soc., 15 (1961) 335.

$17 \mathrm{H}$. H. Jaffe and M. Orchin, Theory and Application of Ultraviolet Spectroscopy, Wiley, New York, 1966.

18 A. M. Trozzolo and W. A. Gibbons, J. Am. Chem. Soc., 89 (1967) 239.

19 R. Huisgen, Angew. Chem., Int. Edn. Engl., 16 (1977) 572.

20 J. J. Pommeret and A. Robert, Tetrahedron, 27 (1971) 2977.

21 A. Robert, J. J. Pommeret, E. Marchand and A. Fouchaud, Tetrahedron, 29 (1973) 463.

22 G. W. Griffin, K. Ishikawa and I. J. Lev, J. Am. Chem. Soc., 98 (1976) 5697.

23 T. M. Leslie, Ph.D. Dissertation, University of Notre Dame, 1980.

A. M. Trozzolo and T. M. Leslie, Bull. Soc. Chim. Belg., 91 (1982) 471.

24 I, J. Lev, K. Ishikawa, N. S. Bhacca and G. W. Griffin, J. Org. Chem., 41 (1976) 2654.

25 G. A. Lee, J. Org. Chem., 41 (1976) 2656.

26 W. Jugelt and L. Berseck, Tetrahedron, 26 (1970) 5581.

27 B. A. Lindig and M. A. J. Rodgers, J. Phys. Chem., 83 (1979) 1683.

28 P. K. Das, M. V. Encinas and J. C. Scaiano, J. Am. Chem. Soc., 101 (1979) 6965.

P. K. Das and S. N. Bhattacharyya, J. Phys. Chem., 85 (1981) 1391.

P. K. Das and K. Bobrowski, J. Chem. Soc., Faraday Trans. II, 77 (1981) 1009.

29 M. A. J. Rodgers, D. C. Foyt and Z. A. Zimek, Radiat. Res., 75 (1978) 296.

30 F. Fichter and H. De Montmollin, Helv. Chim. Acta, 5 (1922) 256.

H. Thoms and J. Schnupp, Justus Liebigs Ann. Chem., 434 (1923) 296.

31 F. Sachs and P. Becherescu, Chem. Ber., 36 (1903) 1132.

32 W. Haensel, Justus Liebigs Ann. Chem., (1976) 1380.

33 G. W. Griffin and P. K. Das, unpublished results, 1982.

34 E. J. Moriconi and J. J. Murray, J. Org. Chem., 29 (1964) 3577.

35 A. M. Trozzolo and E. Wasserman, in R. A. Moss and M. Jones, Jr. (eds.), Carbenes, Vol. 2, Wiley, New York, 1975, Chap. 5, pp. 185 - 206. 